\title{
¿Qué piensan, dicen y hacen los jóvenes universitarios sobre el cambio climático? Un estudio de representaciones sociales
}

\section{Que pensam, dizem e fazem os estudantes universitários sobre a mudança climática? Um estudo das representações sociais}

\section{What do university students think, say and do on climate change? A study of social representations}

\author{
Edgar J. González-Gaudiano ${ }^{1}$ \\ Ana Lucía Maldonado-González ${ }^{1}$
}

\begin{abstract}
RESUMEN
Tratándose de un desafío de global magnitud, el cambio climático amerita de una urgente atención por parte de todos los actores sociales. Aunque exista un pequeño grupo de escépticos que ponga en duda la alta responsabilidad de la actividad humana hacia este fenómeno, es evidente el impacto que el cambio climático ha tenido y tiene sobre los ecosistemas, así como sobre el incremento de los procesos de degradación ambiental. Por tal motivo, es inminente para la protección de los seres humanos y de todas las especies vivas del planeta, priorizar la adopción de medidas de mitigación y de adaptación hacia las causas y consecuencias del cambio climático. En este artículo se presentan los principales resultados de una investigación realizada con el objetivo de conocer la representación social que sobre el cambio climático tienen los jóvenes universitarios. Algunos aspectos teóricos y metodológicos sobre las representaciones sociales y el cambio climático son abordados en la primera parte del artículo. En el estudio participaron estudiantes de las
\end{abstract}

DOI: $10.1590 / 0104-4060.38106$

1 Universidad Veracruzana. Instituto de Investigaciones en Educación, Xalapa, Veracruz, México. Campus Sur. Paseo 112, Lote 2, Sección 2A, Edificio B, 2. ${ }^{\circ}$ piso, Colonia Nuevo Xalapa, C.P. 91097. 
cinco sedes de la Universidad Veracruzana, de nivel licenciatura y posgrado. Entre los hallazgos se detectó que la información científica transmitida por diversas fuentes, científicas y populares, no es suficientemente influyente entre los jóvenes para generar cambios de comportamiento, orientados a frenar el cambio climático. Se recomiendan nuevas estrategias de comunicación y de educación ambiental dirigidas a generar conductas ambientalmente sustentables.

Palabras clave: cambio climático; representación social; jóvenes universitarios; Veracruz; México.

\title{
RESUMO
}

Sendo um desafio de escala global, a mudança climática merece atenção urgente de todos os interessados. Embora haja um pequeno grupo de céticos que duvidam da alta responsabilidade da atividade humana em relação a este fenômeno, é evidente o impacto que a mudança climática teve e tem sobre os ecossistemas, bem como sobre o aumento dos processos de degradação ambiental. Portanto, é iminente, para a proteção de seres humanos e de todas as espécies vivas do planeta, priorizar ações de mitigação e adaptação às causas e consequências das alterações climáticas. Neste artigo se apresentam os principais resultados de uma investigação, realizada com o objetivo de compreender as representações sociais sobre a mudança climática que têm os alunos universitários. Alguns aspectos teóricos e metodológicos das representações sociais e das mudanças climáticas são abordados na primeira parte do artigo. $\mathrm{O}$ estudo incluiu os estudantes dos cinco campi da Universidade Veracruzana, nível de graduação e pós-graduação. Entre os resultados, verificou-se que a informação científica recebida de várias fontes, científicas e populares, não é suficientemente influente entre os jovens para gerar mudanças de comportamento que visem a conter a mudança climática. Novas estratégias de comunicação e educação ambiental voltadas à geração de comportamentos ambientalmente sustentáveis são recomendadas.

Palavras-chave: mudança climática; representação social; estudantes universitários; Veracruz; México.

\begin{abstract}
Being a challenging of global scale, climate change warrants urgent attention from all stakeholders. Although there is a small group of skeptics who doubt the high responsibility of human activity towards this phenomenon, it is clear the impact that climate change has had and has on ecosystems, as well as on increasing the processes of environmental degradation. Therefore, it is imminent for the protection of human beings and all living species on the
\end{abstract}


planet to prioritize actions on mitigation and adaptation to the causes and consequences of climate change. The main results of an investigation aiming at understanding the social representation on climate change by university students are presented in this article. Some theoretical and methodological aspects of the social representations and climate change are addressed in the first part of the article. The study included students from the five campuses of the Universidad Veracruzana, from undergraduate and postgraduate levels. Among the findings it was found that the scientific information received from various sources, scientific and popular, is not sufficiently influential among young people to generate behavioral changes aimed at curbing climate change. New communication and environmental education strategies aimed at generating environmentally sustainable behaviors are recommended.

Keywords: climate change; social representation; university students; Veracruz; Mexico.

\section{Introducción}

Los desafíos impuestos por el cambio climático tanto a nivel personal como colectivo son múltiples; se trata de un fenómeno complejo que, pese a ello, goza de una baja prioridad social y política frente a otros problemas locales y globales, tales como: pobreza, hambre, inseguridad, desempleo, etc. Estos problemas, que también afectan a la población, suelen percibirse con mayor proximidad en tiempo y espacio, de ahí su prioridad en la agenda pública. Aunado a esto, hay que vencer las resistencias para reconocer las causas antropocéntricas del cambio climático que se generan en los círculos de las fuerzas dominantes de la economía mundial, porque así conviene a sus intereses. Otro desafío se presenta cuando el fenómeno llega a ser reconocido por algunos segmentos de la población, pero es necesario romper la brecha entre actitudes y comportamientos. El conocimiento y la sensibilidad de un tema, en este caso el cambio climático y sus repercusiones, no siempre se traducen en acciones responsables que contribuyan a la mitigación del mismo.

Los desafíos antes mencionados competen a múltiples actores: públicos, privados, sociales, científicos, tecnológicos. Acciones individuales e institucionales han permitido que el cambio climático global haya alcanzado la magnitud actual. La población en su conjunto juega sin duda un papel clave, dado que el éxito o el fracaso de las medidas que se propongan o impongan dependerá de cambios de comportamientos y voluntades orientadas hacia otras formas de consumo y estilo de vida que permitan presionar desde abajo hacia la construc- 
ción de nuevos esquemas y políticas públicas de respuesta que tengan como reto poner un freno al cambio climático.

La investigación que aquí se presenta explora, en la población estudiantil de la Universidad Veracruzana (UV), aspectos relacionados con el reconocimiento social del cambio climático como problema y su magnitud; la valoración de los riesgos actuales y potenciales; las fuentes de información sobre el tema; la forma como se incorpora la información científica recibida; las prácticas cotidianas de educación ambiental relacionadas con la mitigación de Gases de Efecto Invernadero (GEI), tales como ahorro de energía, prácticas de consumo, etc.; las posibles medidas de adaptación asumidas voluntariamente y las barreras y disposiciones a actuar hacia un cambio radical de estilo de vida. Estos aspectos fueron analizados a través de la información recabada mediante un instrumento validado y piloteado previamente entre la población veracruzana.

Fueron seleccionadas muestras aleatorias representativas de cada uno de los cinco campus de la Universidad Veracruzana y una más con estudiantes de nivel posgrado, considerando género, nivel y área de estudio. El cuestionario se aplicó de manera personal en los diferentes planteles de la UV entre jóvenes estudiantes. Los resultados, manejados de manera estadística y descriptiva, permiten reconocer las representaciones sociales del cambio climático en la población de jóvenes estudiantes, partiendo del supuesto que dicha población está en condiciones de aportar perspectivas a menudo ignoradas en la política pública, aunque los jóvenes constituyen uno de los sectores mayoritarios en México y de mayor vulnerabilidad. Los jóvenes universitarios constituyen un grupo poblacional con características similares a las de un amplio segmento de la población mexicana, por lo que con los resultados obtenidos se trabajará en la construcción de nuevas herramientas y estrategias pedagógicas, programas de comunicación en educación ambiental, materiales didácticos y autodidácticos, con los que se buscará tener mayores posibilidades de incidir no sólo en el conocimiento de este tema, sino en los valores, actitudes y cambios de comportamientos de la población a la que se dirijan.

\section{Representaciones sociales sobre el cambio climático en contexto veracruzano}

Mucho se ha hablado sobre la urgente necesidad de modificar actitudes y pautas de comportamiento socialmente aceptadas y hasta promovidas por un modelo de consumo al servicio del capitalismo, pero que en nada resultan 
favorables para frenar el cambio climático. Cada vez más de manera cotidiana se escucha hablar sobre este tema en interacciones personales (familiares, amistades, profesores) o masivas (científicos, tecnólogos, políticos, empresarios), pero la información no siempre es comprendida y menos aún aprehendida por quien la recibe. Tanto la transmisión como la interpretación de un mismo mensaje varían según el canal de difusión, el contexto, experiencias e intereses específicos del emisor y de la población receptora. Se requiere mucho más que la transmisión de un mensaje para llegar a los cambios deseados a nivel de la sociedad. Conviene diseñar estrategias, programas de comunicación y de educación ambiental dirigidos específicamente a cada segmento de la población, en este caso jóvenes universitarios. Para esto es necesario primero conocer rasgos característicos de dicha población y saber cómo recibe, interpreta y adopta la información sobre este tema en particular.

Moscovici (1979) explica que un análisis de las representaciones sociales permite averiguar de la población de estudio lo que se sabe (información), lo que se cree y cómo se interpreta (campo de la representación) y lo que se hace o cómo se actúa (comportamientos). Cabe subrayar que una representación social se construye mediante dos procesos fundamentales: la objetivación y el anclaje. A través del proceso de objetivación la información recibida puede orientarse hacia uno u otro sentido según la interpretación que socialmente le sea asignada, siendo así trasladada al dominio del ser. Por otro lado, en el proceso de anclaje la información alcanza a delimitarse en el dominio del hacer, dado que es aprehendida e insertada en la jerarquía de valores de una sociedad, posicionándose como un saber útil para todos (MOSCOVICI, 1979). En el caso concreto de esta investigación realizada con jóvenes estudiantes, las representaciones sociales sobre el cambio climático han sido co-construidas por los distintos actores sociales pertenecientes a la sociedad civil, al sector público y al sector privado, mediante discursos de orientación diversa que corresponden al universo e intereses de quien difunde el mensaje, a la interpretación de quien lo recibe y que lo retransmite según su campo de representación mediante actitudes, hábitos y comportamientos.

En el caso específico del contexto veracruzano, por su situación geográfica y su riqueza de recursos naturales, de sumo atractivo para su explotación, diversos eventos de tipo meteorológico, fenológico y de riesgo ambiental se han presentado a lo largo y ancho de este territorio. Lo anterior contribuye a marcar de una u otra forma la representación social que la población tiene sobre el cambio climático. Incluso, a menudo para justificar políticas públicas ineficientes y más bien orientadas hacia intereses económicos, se adjudican al cambio climático los desastres provocados por fenómenos naturales, sin considerar que en muchas ocasiones las condiciones de vida de la población 
afectada no son óptimas debido a una deficiente planeación urbana, acorde más a intereses económicos que ambientales, así como a las condiciones de pobreza que orillan a diversas poblaciones a vivir en los márgenes de la ciudad dentro de asentamientos irregulares, con mayor riesgo de inundaciones o deslaves provocados por fenómenos naturales. Aunado a esto se tiene muchas veces el riesgo de industrias vecinas contaminantes, poco responsables social y ambientalmente, mismas que contribuyen con emisiones de gases o desechos tóxicos en suelos y mantos acuíferos.

Por mencionar algunos ejemplos, se tienen los fenómenos hidrometeorológicos en el estado de Veracruz, en 2005 el huracán Stan; en 2008, la tormenta tropical Marco; las inundaciones de 2009; en 2010 el huracán Karl, seguido de la tormenta tropical Matthew. Todos estos eventos provocaron graves daños por el desbordamiento de ríos, inundaciones costeras y deceso de personas (TEJEDA MARTÍNEZ, 2006).

A lo anterior habría que sumar los riesgos ambientales por contaminación industrial, derivados, entre otros, de la Comisión Federal de Electricidad (CFE) con la central nucleoeléctrica de Laguna Verde y Petróleos Mexicanos (Pemex) con la termoeléctrica Adolfo López Mateos, la de mayor capacidad en su tipo ubicada en el norte del Estado, generadora de problemas a la salud de la población vecina y de los ecosistemas. Se presenta además contaminación de ríos y costas en el Norte y Sur del estado derivada principal aunque no exclusivamente de las actividades de Pemex. Es el caso del río Coatzacoalcos considerado entre los tres más contaminados del mundo. Los miles de kilómetros de ductos de la petrolera que atraviesan el territorio veracruzano se encuentran en mal estado y reciben poco mantenimiento, por lo que representan un grave factor de riesgo para muchas localidades. Adicionalmente, diversas actividades productivas y humanas han ocasionado sobreexplotación de recursos naturales en bosques y mantos acuíferos, pérdida de diversidad biológica, de fertilidad de suelos, de calidad y cantidad de agua, incidencia de plagas, además de los deficientes manejos de desechos tanto industriales como domésticos y sanitarios en varias localidades (GOBIERNO DEL ESTADO DE VERACRUZ, 2005).

En este contexto, resulta urgente crear programas que contribuyan a la protección civil y el bienestar de la población y de los ecosistemas de manera continua y permanente, programas en los que la misma población se involucre, participe, cambie comportamientos e impulse políticas públicas en este sentido. Para propiciar lo anterior, nuestra investigación proporciona un diagnóstico de la representación social que tiene el segmento de jóvenes universitarios sobre el cambio climático. Es con esto posible conocer lo que piensan, lo que dicen y lo que hacen al respecto, con lo cual será posible diseñar mejores estrategias de comunicación y de educación ambiental que contribuyan a frenar este complejo fenómeno. 


\section{Principales hallazgos: canales y fuentes de información sobre cambio climático}

Antes de ahondar en lo que piensan, lo que dicen y lo que hacen los jóvenes universitarios con respecto al cambio climático, cabe destacar que se trata de un tema altamente difundido en la actualidad por muy diversos medios de información, donde participan representantes del gobierno federal, estatal, local, sector privado, grupos ecologistas, científicos, profesores y educadores ambientales, cada uno de ellos con visiones particulares sobre este complejo fenómeno. Aunque los mensajes enviados y los canales utilizados para emitirlos son múltiples, la interpretación y la comprensión de estos varían de acuerdo a intereses y contextos específicos de cada receptor.

En el caso de la investigación que da origen a este artículo, los jóvenes universitarios reconocen casi en su totalidad que la televisión es el primer medio por el cual reciben información sobre cambio climático, seguida ésta de internet y de las redes sociales. La información sobre cambio climático recibida a través de estos canales no goza de alta confiabilidad entre los jóvenes, pues no siempre es posible alcanzar una retroalimentación que permita pasar del proceso informativo al comunicativo; el intercambio permitiría aclarar dudas y complementar información sobre el complejo fenómeno del cambio climático.

La mayoría de los jóvenes encuestados reconocen como sus fuentes de información más confiables sobre este tema a: 1) los científicos; 2) los grupos ecologistas; 3) los educadores ambientales; 4) los organismos de Naciones Unidas; y 5) los profesores. Pero de estas cinco fuentes, son los grupos ecologistas y los profesores quienes son considerados por los jóvenes como principales emisores de información sobre cambio climático. Además mencionan a familiares, amistades y periodistas, pero con un menor nivel de confianza. Se trata de fuentes éstas últimas con las que tienen mayor cercanía y accesibilidad en sus contextos y con las que existe posibilidad de diálogo, interacción e intercambio. "El origen y la confianza hacia el medio constituyen elementos determinantes en la apropiación o no del mensaje, pero además determinan la reorientación de conductas y comportamientos que contribuyan a frenar el cambio climático" (GONZÁLEZ-GAUDIANO; MALDONADO-GONZÁLEZ, 2013, p. 126). La Figura 1 muestra el proceso de comunicación sobre este tema en los jóvenes y los niveles de confianza que reconocen hacia las distintas fuentes que lo difunden.

Aunque la mayoría de los jóvenes encuestados afirma haber escuchado hablar sobre términos como cambio climático, calentamiento global, agujero de la capa de ozono, dióxido de carbono, esto no significa que conozcan, comprendan y emprendan acciones para frenar el cambio climático. Tampoco 


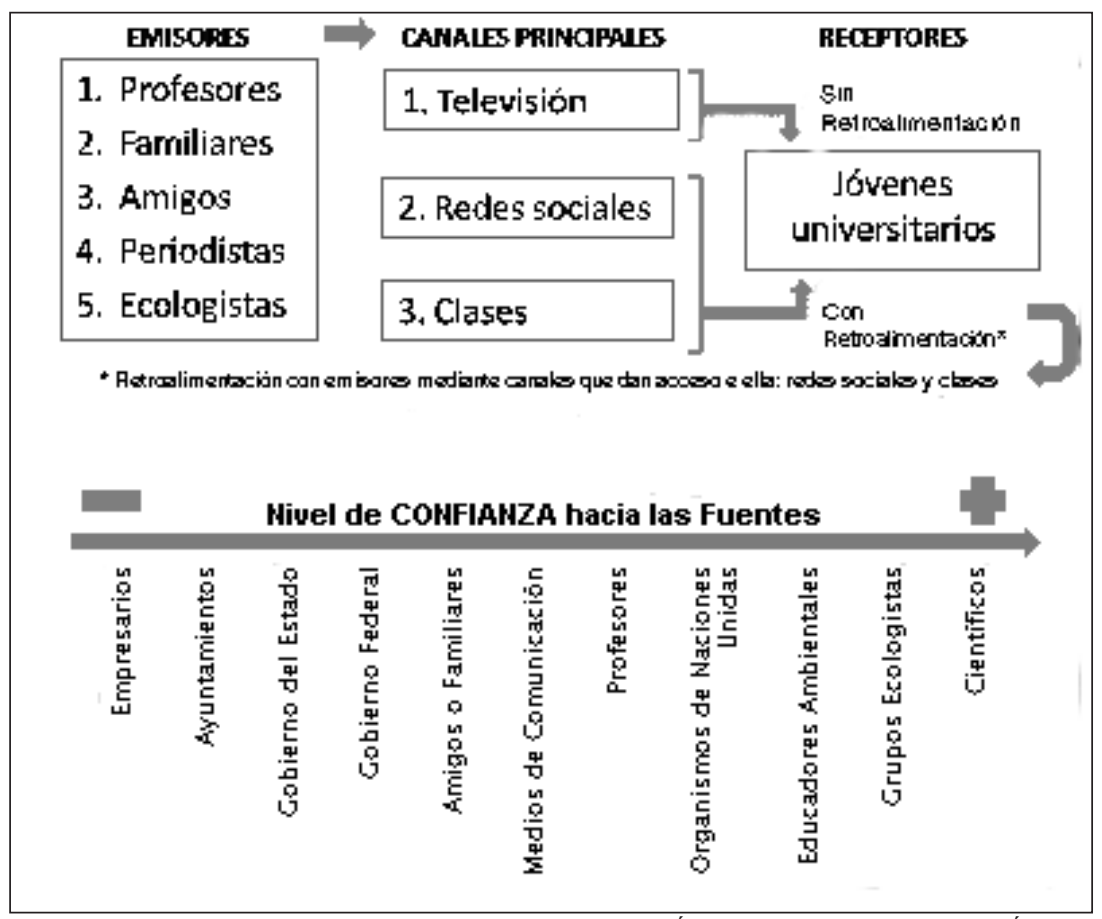

FIGURA 1 - EMISORES Y CANALES DE INFORMACIÓN SOBRE CAMBIO CLIMÁTICO EN JÓVENES UNIVERSITARIOS

FUENTE: González-Gaudiano y Maldonado-González (2013, p. 234).

tienen una idea certera de sus causas y consecuencias. En su mayoría aseguran erróneamente que el cambio climático es un resultado del agujero en la capa de ozono y que la lluvia ácida es una de sus consecuencias. Estas confusiones relacionadas con la capa de ozono como causa o consecuencia del cambio climático se han reportado en otros estudios similares (HEARGREAVES et al., 2004 apud MEIRA-CARTEA, 2009; MEIRA-CARTEA, 2009). Asimismo, esta investigación ratifica lo encontrado por Meira-Cartea (2009), Dunlap (1998) y Stern, Dietz y Guagnano (1995), en relación con el hecho de que la información científica difundida para alfabetizar sobre el cambio climático suele ser confusa, por lo que no se interpreta correctamente. Al respecto, Moscovici (1979) explica que cuando los conocimientos van de arriba hacia abajo; es decir, de los expertos que diseminan el conocimiento hacia la masa de los que ignoran y que imitan a quienes saben, sin permitir llegar al intercambio, difícilmente se alcanzan a modificar cualitativamente las experiencias y teorías de esta masa 
que recibe la información. Veamos ahora qué piensan los jóvenes universitarios con respecto al cambio climático.

\section{¿Qué piensan?}

El primer pensamiento o imagen que llega a la mente de los jóvenes, cuando escuchan hablar sobre cambio climático, está más relacionado con las consecuencias de este fenómeno que con sus causas. Es así que privilegian pensamientos relacionados con cambio y variabilidad climática (cambios bruscos de temperatura; frío o calor extremos), calentamiento global (deshielo de los polos; imagen del mundo sobre una hornilla; la gente quemándose; oso polar en pedazo de hielo sin posibilidad de seguir viviendo), fenómenos naturales (inundaciones, desastres, catástrofes, terremotos, temblores, ciclones), destrucción del medio físico (deforestación, especies en peligro de extinción, trastornos a los ecosistemas). En menor proporción pero presentes se encuentran pensamientos que asocian al cambio climático con el fin del mundo (algo catastrófico como el apocalipsis; destrucción de la raza humana; muerte; desesperación; desequilibrio). Son minoría quienes refieren a pensamientos relacionados con escasez de agua, salud y escasez de alimentos, cuando escuchan hablar del cambio climático. Pensamientos relacionados con la responsabilidad antrópica y con la contaminación derivada de la actividad humana no se registran en alto índice entre los jóvenes encuestados, con lo que es posible apreciar el bajo reconocimiento que se otorga de manera espontánea a las causas que se encuentran en el origen del cambio climático.

La anterior información proviene de la pregunta abierta que cuestiona sobre el primer pensamiento o imagen que llega a la mente de los jóvenes cuando escuchan hablar sobre cambio climático. Tratándose de una pregunta abierta, emergieron en total 303 pensamientos distintos, por lo que para su análisis fue necesario agruparlos en Conceptos Integradores de Respuesta (CIR), y los principales son los que hemos detallado. Esto nos permitió determinar los principales pensamientos de los jóvenes, en relación con este fenómeno global. En la Tabla 1 se incluyen las palabras con mayor número de menciones entre los pensamientos e imágenes que los jóvenes fabrican relacionadas con el cambio climático; fue identificada una palabra primaria y posteriormente palabras secundarias inmersas en aquella, incluyendo el número de menciones correspondientes a cada una de ellas. El contexto y el dominio experiencial influyen en esta representación que sobre el cambio climático tienen los jóvenes. 
Es importante aclarar que esto sólo nos da una idea del número de menciones de palabras primarias y secundarias, sin que por ello correspondan éstas siempre al mismo CIR. Para asignar a los pensamientos en cada CIR, fue necesario analizar el contexto completo del pensamiento. Un ejemplo de esto es la palabra "mundo", la cual se menciona en distintos pensamientos o imágenes que los jóvenes tienen cuando escuchan hablar sobre cambio climático y que agrupamos en los siguientes CIR: 1) Responsabilidad antrópica (hemos abusado mucho de nuestro mundo, de nuestra madre tierra; nos estamos acabando con el mundo); 2) Contaminación (muchos coches en el mundo; el mundo destruido por la contaminación); 3) Calentamiento global (imagen del mundo sobre una hornilla; el mundo siendo afectado por un aumento de temperatura); 4) Cambio y variabilidad climática (las variaciones extremas del clima que afectan la estabilidad del mundo); 5) Fenómenos naturales (desastre natural, cambio en todo el mundo; cambios repentinos en diferentes partes del mundo, desastres climáticos); 6) Fin del mundo (el mundo patas-arriba; destrucción del mundo, fin del mundo). Es posible apreciar las múltiples imágenes que puede contener una misma palabra y considerar estos aspectos en el desarrollo de estrategias de comunicación y de educación ambiental.

Ahora bien, interesa en este punto relacionado con "el pensar" de los jóvenes sobre el cambio climático, la respuesta a la pregunta inicial de nuestro cuestionario, cuando aún no se habla sobre cambio climático. En esta primera pregunta se solicitaba a los jóvenes mencionar los dos principales problemas que más afectan en los contextos mundial, nacional, estatal y municipal. A partir de sus respuestas, es posible afirmar que de manera espontánea y en respuesta a esta primera pregunta abierta, los jóvenes no piensan en el cambio climático como uno de los dos principales problemas que más afectan estos distintos contextos analizados. Son los problemas relacionados con la inseguridad, violencia, delincuencia; así como los problemas económicos y políticos, los que mayor reconocimiento alcanzan en el contexto cercano a los jóvenes, es decir a nivel municipal y estatal. Aunque el cambio climático no es considerado espontáneamente por los jóvenes como un problema principal, sí identifican otros que tienen relación con éste, tales como: contaminación, calor extremo e inundaciones. Se trata de problemas que metafóricamente dan imagen al cambio climático y es así como se van dibujando en los primeros pensamientos o imágenes que llegan a su mente cuando escuchan hablar de cambio climático. Se habla de imagen metafórica porque "[...] la forma concreta que adoptan el conocimiento de contenido racional y las representaciones sociales en la mente de quienes las portan, puede compararse de forma efectiva con las imágenes y las metáforas" (WAGNER; HAYES; FLORES PALACIOS, 2011, p. 114). Estos autores agregan que son tres las partes que componen una metáfora: 1) el 
TABLA 1 - PALABRAS MÁS MENCIONADAS EN LOS PENSAMIENTOS O IMÁGENES QUE LOS JÓVENES ELABORAN CUANDO ESCUCHAN HABLAR DE CAMBIO CLIMÁTICO

\begin{tabular}{|c|c|c|c|c|}
\hline $\begin{array}{l}\text { PALABRA } \\
\text { PRIMARIA } \\
\text { (PP) }\end{array}$ & $\begin{array}{l}\text { Menciones } \\
\text { (PP) }\end{array}$ & $\begin{array}{c}\text { PALABRAS } \\
\text { SECUNDARIAS } \\
\text { (PS) }\end{array}$ & $\begin{array}{l}\text { Menciones } \\
\text { (PS) }\end{array}$ & $\begin{array}{c}\text { Menciones } \\
\mathrm{PP}+\mathrm{PS}=\mathrm{CIR}\end{array}$ \\
\hline \multirow{7}{*}{ Clima/climático } & \multirow{7}{*}{31} & Calor & 54 & \multirow{7}{*}{189} \\
\hline & & Frío & 30 & \\
\hline & & Sol & 7 & \\
\hline & & Temperatura & 21 & \\
\hline & & Cambio & 29 & \\
\hline & & Variación, variabilidad & 10 & \\
\hline & & Drástico & 7 & \\
\hline \multirow{5}{*}{ Desastre } & \multirow{5}{*}{18} & Destrucción & 14 & \multirow{5}{*}{71} \\
\hline & & Catástrofe & 5 & \\
\hline & & Contaminación & 20 & \\
\hline & & Extinción & 5 & \\
\hline & & Muerte & 9 & \\
\hline \multirow{4}{*}{$\begin{array}{c}\text { Natural, } \\
\text { naturales } \\
\text { (fenómenos) }\end{array}$} & \multirow{4}{*}{18} & Lluvia & 15 & \multirow{4}{*}{55} \\
\hline & & Inundación & 12 & \\
\hline & & Huracanes & 5 & \\
\hline & & Terremoto & 5 & \\
\hline \multirow{3}{*}{ Polos } & \multirow{3}{*}{23} & Derretir/derretimiento & 14 & \multirow{3}{*}{54} \\
\hline & & Deshielo/hielo & 14 & \\
\hline & & Oso polar & 3 & \\
\hline \multirow{2}{*}{ Mundo } & \multirow{2}{*}{20} & Tierra & 6 & \multirow{2}{*}{42} \\
\hline & & Planeta & 16 & \\
\hline \multirow{4}{*}{ Naturaleza } & \multirow{4}{*}{4} & Medio Ambiente & 11 & \multirow{4}{*}{40} \\
\hline & & Agua & 14 & \\
\hline & & Animales & 6 & \\
\hline & & Capa de ozono & 5 & \\
\hline \multirow{5}{*}{ Humano } & \multirow{5}{*}{11} & Hombre & 1 & \multirow{5}{*}{27} \\
\hline & & Personas & 4 & \\
\hline & & Salud & 4 & \\
\hline & & Enfermedades & 4 & \\
\hline & & Nosotros & 3 & \\
\hline
\end{tabular}

FUENTE: González-Gaudiano y Maldonado-González (2013, p. 158).

dominio de la experiencia; 2) el dominio del otro; y 3) la relación de correspondencia entre ambos dominios. Es decir, se tiene a la experiencia personal como lo más cercano y arraigado al sujeto, es concreto; luego se tiene el dominio del otro, alejado de la experiencia personal, es abstracto y menos comprensible. 
Sin embargo, tanto el dominio experiencial como el dominio del otro pueden estar ligados cuando hay un esfuerzo constructivo en la comunicación y el discurso, estableciendo similitudes estructurales entre ambos dominios, alcanzando así una relación estructural llamada correspondencia (mapping). Es decir, cuando la metáfora icónica del dominio experiencial se comunica al dominio del otro, entonces lo concreto personal recorre lo abstracto del otro y llega a ser concreto para éste también (LAKOFF, 1987, apud WAGNER; HAYES; FLORES PALACIOS, 2011, p. 115), siendo ésta una forma de construcción de la representación social. Específicamente en la pregunta relacionada con los dos principales problemas que más afectan a los distintos contextos, es posible apreciar que la imagen metafórica del cambio climático permanece aún abstracta para la mayoría de los encuestados. Esto se debe probablemente a que no se encuentra aún en su dominio experiencial, donde identifican a otras imágenes más cercanas a la contaminación y a los fenómenos naturales, si bien relacionadas estos estrechamente con el cambio climático, no lo aluden directamente. Tratándose ésta de una pregunta abierta, fueron muy diversos los problemas enlistados para cada contexto, varios relacionados entre sí, por lo que para esta pregunta también fue necesario determinar lo CIR donde fuera posible agrupar a problemas similares para su análisis correspondiente. La Tabla 2 muestra el número de primeras y segundas respuestas para cada contexto, así como el total de conceptos integradores de respuestas, que fue necesario crear.

TABLA 2 - NÚMERO DE RESPUESTAS DISTINTAS OBTENIDAS A DOS PRINCIPALES PROBLEMAS QUE MÁS AFECTAN AL MUNDO, A MÉXICO, AL ESTADO DE VERACRUZ Y AL MUNICIPIO DE CADA ENCUESTADO

\begin{tabular}{lcccc} 
& Mundo & México & Edo. Veracruz & Municipio \\
\hline $1{ }^{\text {a }}$ Respuesta & 110 & 88 & 108 & 130 \\
\hline $2{ }^{\text {a }}$ Respuesta & 133 & 122 & 119 & 141 \\
\hline $\begin{array}{l}\text { N. }{ }^{\circ} \text { de Conceptos } \\
\text { integradores }\end{array}$ & 19 & 18 & 19 & 21 \\
\hline
\end{tabular}

FUENTE: González-Gaudiano y Maldonado-González (2013).

Emergieron en total 23 CIR para los cuatro distintos contextos, los cuales se muestran en la Tabla 3. Aunque el cambio climático se menciona en todos los contextos, es a nivel mundial donde dos de cada diez encuestados lo reconoce en su imaginario dentro de los dos principales problemas, como puede apreciarse en la Gráfica 1.

Debido, a que la imagen del cambio climático permanece abstracta en los distintos contextos, es posible afirmar que no se encuentra en el dominio experiencial de los jóvenes encuestados. Otras imágenes metafóricas tienen 
TABLA 3 - CONCEPTOS INTEGRADORES DE RESPUESTAS (CIR) PARA CADA CONTEXTO

\begin{tabular}{|c|c|c|c|c|c|}
\hline & $\begin{array}{l}\text { Conceptos Integradores de } \\
\text { Respuestas }\end{array}$ & Mundo & México & $\begin{array}{c}\text { Edo. } \\
\text { Veracruz }\end{array}$ & Municipio \\
\hline 1 & Inseguridad/violencia/delincuencia & $\mathrm{x}$ & $\mathrm{x}$ & $\mathrm{x}$ & $\mathrm{x}$ \\
\hline 2 & Contaminación & $\mathrm{x}$ & $\mathrm{x}$ & $\mathrm{x}$ & $\mathrm{x}$ \\
\hline 3 & Pobreza/desigualdad/marginación & $\mathrm{x}$ & $\mathrm{x}$ & $\mathrm{x}$ & $\mathrm{x}$ \\
\hline 4 & Economía & $\mathrm{x}$ & $\mathrm{x}$ & $\mathrm{x}$ & $\mathrm{x}$ \\
\hline 5 & $\begin{array}{l}\text { Cambio climático/calentamiento } \\
\text { global }\end{array}$ & $\mathrm{x}$ & $\mathrm{x}$ & $\mathrm{x}$ & $\mathrm{x}$ \\
\hline 6 & Política & $\mathrm{x}$ & $\mathrm{x}$ & $\mathrm{x}$ & $\mathrm{x}$ \\
\hline 7 & Educación & $\mathrm{x}$ & $\mathrm{x}$ & $\mathrm{x}$ & $\mathrm{x}$ \\
\hline 8 & Valores/ser humano & $\mathrm{x}$ & $\mathrm{x}$ & $\mathrm{x}$ & $\mathrm{x}$ \\
\hline 9 & Medio ambiente/deterioro & $\mathrm{x}$ & $\mathrm{x}$ & $\mathrm{x}$ & $\mathrm{x}$ \\
\hline 10 & Fenómenos naturales & $\mathrm{x}$ & $\mathrm{x}$ & $\mathrm{x}$ & $\mathrm{x}$ \\
\hline 11 & Salud & $\mathrm{x}$ & $\mathrm{x}$ & $\mathrm{x}$ & $\mathrm{x}$ \\
\hline 12 & Escasez de agua & $\mathrm{x}$ & $\mathrm{x}$ & $\mathrm{x}$ & $\mathrm{x}$ \\
\hline 13 & Analfabetismo & $\mathrm{x}$ & $\mathrm{x}$ & $\mathrm{x}$ & $\mathrm{x}$ \\
\hline 14 & Adicciones & $\mathrm{x}$ & $\mathrm{x}$ & $\mathrm{x}$ & $\mathrm{x}$ \\
\hline 15 & Migración & $\mathrm{x}$ & $\mathrm{x}$ & $\mathrm{x}$ & $\mathrm{x}$ \\
\hline 16 & Hambruna & $\mathrm{x}$ & & $\mathrm{x}$ & $\mathrm{x}$ \\
\hline 17 & Población & $\mathrm{x}$ & $\mathrm{x}$ & & $\mathrm{x}$ \\
\hline 18 & Falta de recursos al campo & & $\mathrm{x}$ & $\mathrm{x}$ & $\mathrm{x}$ \\
\hline 19 & Escasez de alimentos & $\mathrm{x}$ & $\mathrm{x}$ & & \\
\hline 20 & Desarrollo urbano & & & $\mathrm{x}$ & $\mathrm{x}$ \\
\hline 21 & Sociedad civil & & & $\mathrm{x}$ & $\mathrm{x}$ \\
\hline 22 & Consumismo & $\mathrm{x}$ & & & \\
\hline 23 & Vialidad vehicular & & & & $\mathrm{x}$ \\
\hline
\end{tabular}

FUENTE: González-Gaudiano y Maldonado-González (2013, p. 135).

mayor presencia en su dominio experiencial, concreto, a ellas refieren y son posibles formas en las que pueden estar representando al cambio climático o acercarse a este fenómeno a través de otro problema concreto, en su dominio experiencial, menos abstracto, en el dominio del otro. Dichas imágenes fueron agrupadas como se muestra en el Cuadro 4, dentro de los CIR correspondientes.

Se trata de palabras o frases que guardan relación con las causas o consecuencias del cambio climático y se encuentran en la representación social que sobre este fenómeno tienen los jóvenes universitarios, por lo que resulta importante considerarlas en el diseño de estrategias de comunicación y de educación ambiental; provienen de este segmento poblacional y es un lenguaje que identifican y se encuentra en su dominio experiencial, para estos contextos particulares de estudio. Veamos ahora lo que dicen con respecto al cambio climático. 


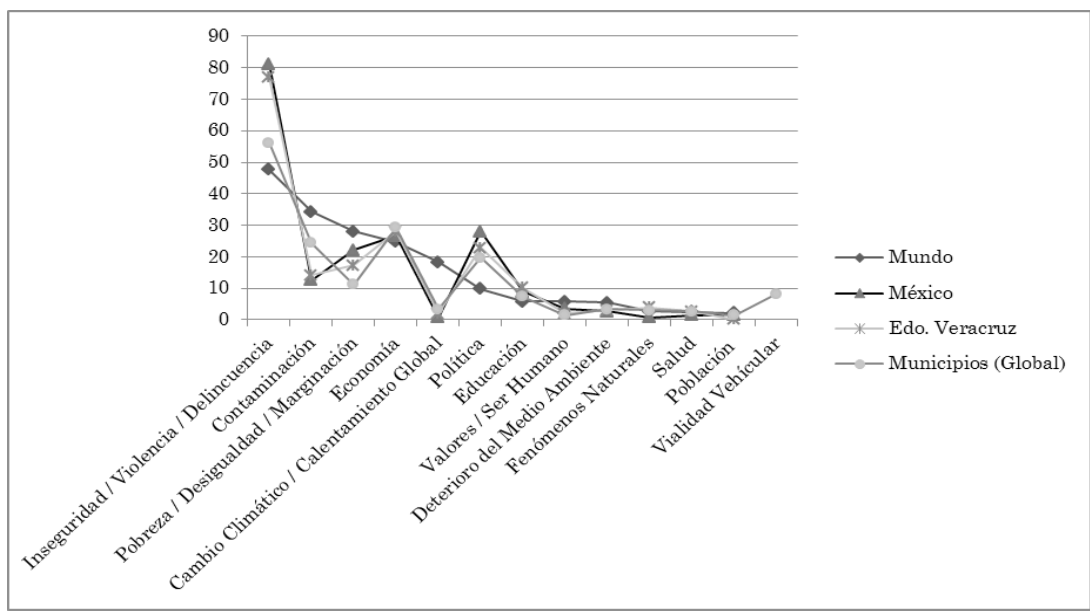

GRÁFICA 1 - PRINCIPALES PROBLEMAS QUE MÁS AFECTAN AL MUNDO, A MÉXICO, AL EDO. VERACRUZ Y MUNICIPIOS (SUMA DE PRIMERA Y SEGUNDA RESPUESTA - \%)

FUENTE: González-Gaudiano y Maldonado-González (2013, p. 143).

- CAMBiO CLIMÁTICO: 1) calentamiento global; 2) calor; 3) cambios de clima constante; 4) clima; 5) clima extremo; 6) clima variado; 7) climáticos; 8) el clima caluroso.

GEI: 1) Concentración de gases de efecto invernadero; 2) efecto invernadero.

- FENÓMENOS NATURALES: 1) desastres ambientales; 2) desastres naturales; 3) el problema ambiental, está temblando en todo el mundo; 4) inundaciones; 5) las tormentas (ciclones, huracanes); 6) lluvias.

- CONTAMINACIÓN: 1) acumulación de basura; 2) basura; 3) contaminación a la atmósfera; 4) contaminación ambiental; 5) contaminación auditiva; 6) contaminación de basura; 7) contaminación de la atmósfera y suelo; 8) contaminación de la tierra; 9) contaminación de las playas; 10) contaminación de los automóviles; 11) contaminación de ríos, mar y océanos; 12) contaminación de suelos; 13) contaminación del agua; 14) contaminación del aire (humo); 15) contaminación industrial; 16) contaminación, la playa muy sucia; 17) contaminación mundial a causa de los eventos mundiales; 18) deshecho; 19) futura contaminación ambiental; 20) inadecuada disposición de residuos y materiales tóxicos; 21) industrias que producen gases tóxicos; 22) la quema de basura; 23) limpieza pública; 24) limpieza, es una ciudad muy sucia; 25) los dos ingenios azucareros contaminan el agua; 26) los desechos tóxicos que se llevan al mar; 27) no saber separar la basura; 28) recolección de basura.

- DEFORESTACIÓN: 1) cambio de uso de suelo; 2) deforestación de bosques; 3) deforestación de árboles; 4) erosión de suelos; 5) incendios; 6) mal uso del suelo; 7) tala de árboles; 8) tala inmoderada.

CUADRO 4 - CIR RELACIONADOS CON CAMBIO CLIMÁTICO Y LAS IMÁGENES METAFÓRICAS COMPRENDIDAS EN ELLOS

(continua) 
(conclusión)

- CAMPO: 1) abandono de la tierra; 2) apoyos al campo; 3) el campo; 4) falta de inversión al campo; 5) la baja productividad en la mayoría del campo mexicano; 6) no fomentar la producción; 7) poco recurso en el campo.

- DETERIORO DEL MEDIO AMBIENTE: 1) el hambre de las trasnacionales por los recursos; 2) problemas ambientales; 3) daño al medio ambiente; 4) daño ecológico al planeta; 5) destrucción de la biodiversidad; 6) deterioro ambiental; 7) deterioro del medio ambiente; 8) el daño al medio ambiente; 9) el rápido agotamiento de los recursos fósiles; 10) explotación de suelos; 11) extinción de especies; 12) falta de recursos energéticos limpios; 13) la falta de hidrocarburos; 14) la falta de recursos naturales; 15) mal cuidado del ambiente; 16) medio ambiente; 17) pérdida de biodiversidad; 18) tráfico de especies; 19) capa de ozono; 20) deterioro de la capa de ozono.

- AGUA: 1) agua potable; 2) corte del agua; 3) escasez de agua; 4) falta de agua; 5) falta de agua potable; 6) problemas del agua; 7) un sistema de agua potable eficiente.

- ALIMENTOS: 1) comida; 2) crisis alimentaria; 3) el aumento en los precios de los productos básicos; 4) el incremento de precios de productos; 5) escasa comida; 6) falta de alimento; 7) hambre; 8) hambruna; 9) la hambruna en diversas zonas del mundo.

- SALUD: 1) desnutrición; 2) enfermedades; 3) enfermedades solares en este periodo; 4) enfermedades transmisibles; 5) obesidad; 6) problemas de la salud; 7) sanidad; 8) servicios de salud.

- POBLACIÓN: 1) alto índice de población; 2) aumento de población; 3) sobrepoblación.

- TRÁfiCO VEHICULAR: 1) automóviles; 2) caos vial; 3) exceso de automóviles; 4) exceso de taxis; 5) la distribución vial; 6) tráfico; 7) tráfico intenso; 8) tráfico vehicular; 9) tráfico-vialidad; 10) vialidad.

- CONSUMISMO: 1) consumismo exagerado; 2) consumo excesivo de recursos no renovables; 3) consumismo.

- DESARROLlO URBANO: 1) crecimiento excesivo; 2) demasiados automóviles y mala planeación de la ciudad; 3) desarrollo; 4) falta de áreas recreativos; 5) falta de urbanización; 6) inundaciones en calles y avenidas; 7) inundaciones, mala planeación; 8) pocas áreas verdes.

- VALORES Y EA: 1) apatía; 2) apatía de la gente; 3) avaricia; 4) concientizar a la gente sobre la basura; 5) conducta negativa social; 6) deshonestidad; 7) ecología, falta de concientización de la gente; 8) falta de apoyo a los programas que cuidan el medio ambiente; 9) falta de educación ambiental; 10) falta de iniciativa para aprovechar recursos naturales; 11) falta de iniciativa para fomentar recursos energéticos; 12) falta de valores (respeto) a lo que se refiere a la vida; 13) irresponsabilidad social; 14) falta de conciencia; 15) la falta de valores; 16) la indiferencia; 17) pérdida de valores; 18) pérdida de valores, prepondera lo económico sobre lo social y ecológico.

CUADRO 4 - CIR RELACIONADOS CON CAMBIO CLIMÁTICO Y LAS IMÁGENES METAFÓRICAS COMPRENDIDAS EN ELLOS

FUENTE: González-Gaudiano y Maldonado-González (2013, p. 139-141).

\section{¿Qué dicen?}

La información científica sobre el cambio climático que reciben los jóvenes universitarios es objetivada, pasando del pensar al decir; los jóvenes se 
convierten así en emisores y transformadores de la información, es entonces cuando se apropian del tema del cambio climático y lo representan socialmente según su dominio experiencial, influenciado por su contexto. En el decir tenemos lo que los jóvenes transmiten sobre el cambio climático, influenciado por su experiencia vivida. Es la objetividad de este fenómeno transformada en subjetividades constituidas y compartidas con otros, la conciencia individual fusionada con la colectiva, compartida en el grupo social, lo que viene a afectar el plano emocional y la identidad de sus miembros (JODELET, 2006). Por su parte, Moscovici (1979) explica que en las representaciones sociales existe la posibilidad de una objetividad variable de su fuente, siendo influenciadas por las prácticas y los valores de los sujetos, quienes dan al objeto, en este caso al cambio climático, un sentido específico, desencadenando así transformaciones y quizá conflictos en la sociedad y en la estructura de la representación social sobre el cambio climático. Cuando estas experiencias son comunicadas y compartidas mediante el decir de los jóvenes, es cuando guardan un lazo con las representaciones sociales, la experiencia se convierte en social y en socialmente construida al mismo tiempo (JODELET, 2006). Es así que en este nivel inciden los dos procesos que conforman la representación social: los procesos cognitivos o mentales, de carácter individual que se encuentran en el pensar; y los procesos de interacción y contextuales, de carácter social (BANCHS, 2000). En este caso, buscando explorar posibles consecuencias derivadas del cambio climático en el imaginario de los jóvenes, se les planteó una serie de cuestiones relacionadas con situaciones meteorológicas y fenológicas que pueden o no estar vinculadas científicamente con el cambio climático. Se detecta a través de sus respuestas que la variabilidad climática es cada vez más perceptible para la población, entre siete y nueve de cada diez encuestados coinciden al afirmar que la temporada de invierno ahora es más seca y calurosa; que los veranos son más largos y calurosos; que los huracanes ahora son más intensos y que las estaciones antes eran más definidas, ahora se notan menos. Por otro lado, se cuestiona la presencia en México en los próximos 20 años de ciertos acontecimientos relacionados con el cambio climático. La mayoría de los jóvenes afirma que será muy probable la escasez de agua potable; el aumento significativo a las temperaturas en todo el país; períodos de sequía más frecuentes; pérdida de suelos fértiles e incremento de los incendios forestales. Además, la mayoría de los jóvenes reconoce al cambio climático como agravante de problemas mundiales tales como desnutrición, hambrunas, enfermedades y pobreza. A nivel personal, reconocen que este fenómeno agravará su salud, pues habrá más enfermedades y daños a la salud en general. En su mayoría se saben en cierta forma responsables de este fenómeno, pues siete de cada diez jóvenes admiten que el cambio climático es un fenómeno provocado por la actividad 
humana y dos de cada diez lo adjudican tanto a la actividad humana como a un proceso natural de la Tierra. Sólo 4\% de los encuestados afirma que el cambio climático es un proceso natural de la Tierra y en nada involucra a la actividad humana, argumento no válido para la ciencia según se manifiesta en el último informe del PICC (2007). Entonces, frente a tales escenarios y conscientes de los mismos, ¿qué cambios en conductas y comportamientos han adoptado en los últimos años en relación con el cambio climático?

\section{¿Qué hacen?}

Las experiencias vividas y compartidas derivan en aprendizajes, los cuales influyen en el desarrollo de actitudes y, al mismo tiempo, de nuevos aprendizajes, se trata de un proceso holístico de experiencia-aprendizaje-actitud. Moscovici (1979) explica que las actitudes pueden formarse genéticamente o mediante mecanismos de aprendizaje. Las representaciones sociales son eventos mentales compartidos que incluyen patrones de habla y de acción, hay además selecciones y relaciones de personas y objetos para dar o no seguimiento a lo estipulado por el grupo (MOSCOVICI, 1988, apud WAGNER; HAYES; FLORES PALACIOS, 2011). Por su parte Abric (2001) explica que la representación no sigue y no depende de la evolución que se presenta en una interacción, más bien la precede y determina, por lo que la representación interviene de manera directa en la definición cognitiva que se adoptará ante una situación determinada.

A través de esta investigación fue posible identificar que en sus prácticas relacionadas con el cambio climático, los jóvenes aún actúan más por comodidad individual y por el cuidado de su economía. Algunos ejemplos de esto se encuentran en que prevalece la preferencia hacia el uso de vehículo particular, frente a un transporte público deficiente, rechazando el incremento en combustibles. Además, por un lado aseguran estar dispuestos a invertir en electrodomésticos más eficientes para el ahorro energético en el hogar, pero por otro lado aseguran que ahora gastan más en ventiladores y aire acondicionado, por los efectos del cambio climático.

Las actitudes de los jóvenes frente al cambio climático comprenden la tercera dimensión de las representaciones sociales (MOSCOVICI, 1979). Se trata del actuar de los jóvenes, su disponibilidad hacia crear o modificar acciones y comportamientos en favor del medio ambiente, quizás voluntariamente o quizás en respuesta a programas de Gobierno. Fueron sólo seis las preguntas incluidas en nuestra investigación, relacionadas con el actuar de los jóvenes frente al 
cambio climático, por lo que difícilmente es posible afirmar que tenemos un panorama completo de lo que hacen con respecto a este fenómeno global. Sin embargo, en sus haceres, reiteran la consulta de este tema a través de películas, documentales o internet, corroborando con esto lo que han mencionado sobre los medios masivos más recurrentemente utilizados para informarse sobre este tema. Lo que menos realizan es solicitar información sobre ahorro de energía a alguna dependencia de gobierno, seguido de la participación en programas de ahorro energético, lo que va a la par de la baja confianza que depositan a las autoridades para informarse sobre el cambio climático.

En este contexto, veamos ahora los cambios que específicamente seis de cada diez encuestados afirman haber adoptado en los últimos años y que, a su parecer y en respuesta a una pregunta abierta, están relacionados con el cambio climático. Se hace mayor referencia a cambios relacionados con reducción de energía en el hogar, reciclaje, separación de basura y compostaje, menor consumo y reutilización de agua, compartir auto, uso de transporte público y activo (caminar, bicicleta), focos y aparatos ahorradores.

Por otro lado, aunque mencionados con menor énfasis, hay quienes adoptan otros cambios orientados más bien hacia su propio confort: cambios en el vestir, ropa más ligera, peinado distinto $(6 \%)$, más actividades al interior $(3 \%)$ y más uso de ventiladores y aire acondicionado (2\%). Quizá en este grupo y en el $40 \%$ restante que no ha adoptado cambio alguno, se encuentran jóvenes que no disponen aún de información sobre la gravedad del problema o bien, que están más centrados en sí mismos, tienen poco interés al respecto del cambio climático o la percepción de que el problema no tiene solución, que lo mejor es la autoprotección y que alguien más, quizá un "superhéroe", vendrá a solucionarlo. Asociado esto a "[...] la actitud egótica, la venalidad, la banalidad y el consumismo" que gracias a la eficacia de la socialización que brindan los medios masivos, amenazan con constituirse en factores estructurales de todas las culturas (YURÉN, 1995, p. 7). Es urgente entonces avanzar en otra dirección, más orientada hacia cambios estructurales que trasciendan y transformen también de una manera eficaz la conciencia colectiva. Urge también entonces la concientización a través de programas de educación y de comunicación que propicien cambios reales de estilos de vida y comportamientos individuales, colectivos, institucionales, estructurales, para frenar el cambio climático. Como lo afirman González-Gaudiano y Meira-Cartea (2009) si bien las acciones puntuales de la población pueden tener efectos en el sistema climático, la responsabilidad individual no se agota ahí, es necesario promover con mayor énfasis la adopción de medidas con este fin en todos los diversos ámbitos que definen el estilo de vida occidental. 


\section{A manera de conclusión}

En el contexto de esta investigación y sin ánimos de justificar la mediana acción ambiental de los jóvenes universitarios, sí es posible obtener una lectura sobre las principales preocupaciones que tiene este segmento en la actualidad. Frente a problemas de inseguridad, violencia y delincuencia y frente a la crisis política y económica, se prioriza el propio cuidado, la autoprotección y en la medida de lo posible el propio confort, de manera un tanto egoísta. El cambio climático como tal se dibuja en el pensar de los jóvenes mediante imágenes diversas y catastróficas; sin embargo, no se contempla en el decir dentro de los dos principales problemas que más afectan en la escala local y global. En este contexto, actuar en consecuencia no es muy común, el hacer ambiental es reducido. Sin embargo, los jóvenes reconocen diversas consecuencias del cambio climático, principalmente las relacionadas con los riesgos que representan para la salud humana y los ecosistemas, propiciado esto por una forma de violencia estructural que deteriora la calidad de vida y el bienestar de todo ser vivo en el planeta.

Algunas condiciones que se han sugerido como necesarias para que la sociedad en su conjunto reaccione de manera urgente y colectiva, válidas quizás para cualquier problema social, pero en este caso específico es frente a los desafíos del cambio climático, son: 1) la existencia de una experiencia colectiva de eventos significativos; 2) la presencia de estructuras y organizaciones con capacidad para impulsar la acción; 3) la disponibilidad de soluciones aplicables al problema; y 4) la producción de cambios significativos en valores y actitudes de la población (KATES, 2007, apud MEIRA-CARTEA, 2009). Convendría entonces cuestionarnos sobre estas cuatro condiciones y en qué nivel nos encontramos como sociedad en cada una de ellas. Si bien es cierto que en el estado de Veracruz se han vivido experiencias colectivas en eventos significativos derivados principalmente de fenómenos naturales o de contingencias de la actividad industrial que han ocasionado graves contaminaciones ambientales, no es clara aún la existencia de suficientes estructuras, además competentes y dispuestas a actuar frente a dichos eventos, que logren propiciar cambios más bien proactivos que reactivos, tanto al interior de las mismas como hacia la población en su conjunto. 


\section{REFERENCIAS}

ABRIC, J. C. Las representaciones sociales: aspectos teóricos. En:

(Dir.). Prácticas sociales y representaciones. México, D. F.: Ediciones Coyoacán, 2001. p. 11-32.

BANCHS, M. A. Aproximaciones procesuales y estructurales al estudio de las representaciones sociales. Papers on Social Representations. Textes sur les représentations sociales, n. 9, p. 3.1-3.15, 2000.

DUNLAP, R. E. Lay perceptions of global risk: Public views of global warming in cross-national context. International Sociology, n. 13, p. 473-498, 1998.

GOBIERNO DEL ESTADO DE VERACRUZ. Plan Veracruzano de Desarrollo 2005 2010. 2005. Disponible en: <http://www.culturaveracruz.ivec.gob.mx/ivec/transparencia/ planesyprogramas/PVD2005-2010.PDF>. Acceso en: 20/04/2011.

GONZÁLEZ-GAUDIANO, E.; MALDONADO-GONZÁLEZ, A. L. Los jóvenes universitarios y el cambio climático. Un estudio de representaciones sociales. Veracruz, México: Universidad Veracruzana, 2013. (Colección Biblioteca).

GONZÁLEZ-GAUDIANO, E.; MEIRA-CARTERA, P. A. Educación, comunicación y cambio climático. Resistencia para la acción social responsable. Trayectorias, revista de ciencias sociales de la Universidad Autónoma de Nuevo León, México: UANL, v. 11, n. 29, p. 6-38, 2009.

JODELET, D. Place de l'expérience vécue dans le processus de formation des représentations sociales. En: HASS, V. Les savoirs du quotidien. Transmissions, Appropriations, Représentations. Rennes: Les Presses Universitaires de Rennes, 2006. (Collection Didact Psychologie Sociale). p. 235-255. Disponible en: <http://www.uqac.ca/jmt-sociologue/>. Acceso en: 23/05/2011.

MEIRA-CARTEA, P. A. Comunicar el cambio climático. Escenario social y líneas de actuación. Madrid: Ministerio de Medio Ambiente y Medio Rural y Marino, Organismo Autónomo de Parques Nacionales, 2009.

MOSCOVICI, S. El psicoanálisis, su imagen y su público. Buenos Aires: Editorial Huemul, 1979.

PICC. Cambio climático 2007: Informe de síntesis. Contribución de los Grupos de trabajo I, II y III al Cuarto Informe de evaluación del Grupo Intergubernamental de Expertos sobre el Cambio Climático [Pachauri, R. K. y A. Reisinger (Dirs.).] Ginebra, Suiza: OMM-PNUMA, 2007.

STERN, P.; DIETZ, T.; GUAGNANO, G. The new ecological paradigm in socialpsychological context. Environment and Behaviour, v. 27, n. 6, p. 723-743, 1995.

TEJEDA MARTÍNEZ, A. Panorámica de las inundaciones en el Estado de Veracruz durante 2005. En: TEJEDA MARTÍNEZ, A.; WELCH RODRÍGUEZ, C. (Coords.). 
Inundaciones 2005 en el Estado de Veracruz. México: Covecyt y Universidad Veracruzana, 2006. p. 9-20.

YURÉN, M. T. Eticidad, valores sociales y educación. México: Universidad Pedagógica Nacional, 1995.

WAGNER, W.; HAYES, N.; FLORES PALACIOS, F. (Eds.). El discurso de lo cotidiano y el sentido común: La teoría de las representaciones sociales. México-Barcelona: UNAM-Anthropos, 2011.

Texto recebido em 09 de outubro de 2014. Texto aprovado em 13 de outubro de 2014. 
